\title{
El sistema de rancherías: revisión de conceptos en el contexto de las misiones jesuíticas de la península de California
} (1697-1768)

The rancherías system: review of concepts in the context of the jesuit missions in the California peninsula

(1697-1768)

María del Mar Muñoz González

\section{Resumen}

En este artículo se hace una revisión del concepto de rancho como categoría de análisis, de su capacidad explicativa para el contexto territorial de la Baja California y de su uso para calificar momentos y características diferenciadas de explotación económica a lo largo de la historia. Interesa particularmente valorar las modificaciones que sufre dicho concepto de rancho desde el modelo de subsistencia estructurado en torno a la organización familiar, a otro de explotación ganadera a gran escala. En todo este proceso veremos cómo se producen flujos y reflujos de las características determinantes de los ranchos, a saber: dependencia del equilibrio medioambiental, movilidad, nomadismo y ganadería.

Palabras clave: misiones, jesuitas, rancho, subsistencia, ganadería

\begin{abstract}
In this article a revision about the rancho's concept as category of analysis is done, about its capacity for explaining the territorial context of the Low California, and about its use to qualify different moments and characteristics of the economic activities through history. Its particularly interesting value the changes of the rancho's concept since the subsistence farming based on the family, and the new concept of commercial cattle ranching. In this process, the main ranchos' characteristics are influenced and changed: dependence of the environmental balance, mobility, nomadism and ranching (cattle).
\end{abstract}

\footnotetext{
* Universidad Pablo de Olavide, Sevilla.
} 
Key words: missions, Jesuits, rancho, subsistence, ranching (cattle)

Recibido: 17 de mayo de 2015

Evaluado: 10 de junio de 2015 


\section{El concepto de rancho: sus orígenes y usos}

Lingüistas y etimólogos apuntan que "en los siglos XVI y XVII rancho era palabra bien conocida en todos los países donde se ha hablado castellano, designando toda clase de viviendas provisionales [...] la aplicaron a las chozas y guaridas de los indios americanos, de donde quedó luego como nombre de vivienda pobre y rural de los habitantes de América, aun los criollos” ${ }^{1}$. La caracterización documental de este vocablo es principalmente americana, para ser exactos hispanoamericana. En el Corpus del Nuevo Diccionario Histórico Español Versión 3.0 se referencia el uso de 'rancho' en el siguiente contexto: "Porque de esta provincia de Tepeaca se hallaron algunas con que pelearon, y en los ranchos y aposentos en que la gente de Culúa estaba en Cuachachula se hallaron asimismo" ${ }^{2}$.

La trayectoria histórica de rancho con referencia significativa de 'vivienda rural o finca de campo' está profusamente fijada en fuentes textuales del Nuevo Mundo, su descripción en la sincronía actual muestra una notable correspondencia con el anterior hecho: se trata, efectivamente, de un americanismo general, aunque con diversas acepciones en la geografía lingüística del otro lado del Atlántico ${ }^{3}$. Sin embargo, también se pueden encontrar referencias tempranas en Andalucía ${ }^{4}$, como por ejemplo en dos pasajes de las Ordenanzas de Carmona, copiadas en 1511 de otras de 1495, vienen a anticipar mucho la fijación de nuestro término en el mapa andaluz:

E que todas las personas que anduvieren por los dichos montes puedan coger e llevar a sus casas del campo o ranchos de la dicha leña quemadiza para quemalla [...]. Y el que tuviere yesca o eslabón en casas pagizas o en sus ranchos o hatos, que tenga la dicha pena ${ }^{5}$.

El Diccionario de la Real Academia Española registra tres acepciones directamente relacionadas con el sentido básico de 'vivienda rural', a saber: 'choza o casa pobre con techumbre de ramas o paja, fuera de poblado' (general), 'finca de labor de menos extensión que el cortijo y por lo común con vivienda' (andaluz) y 'granja donde se crían caballos y otros cuadrúpedos' (americano), a las cuales seguramente habría que añadir, sino es una redundancia de la consignada aquí en primer lugar, la de 'lugar fuera de poblado, donde se albergan diversas familias o personas (rancho de gitanos, de pastores)', también dada como de uso común, igual que la definición única de ranchería, 'conjunto de ranchos o chozas que forman como un lugar' 6 .

Un clarificador recorrido por los documentos que recogen el significado de la voz rancho a través de los siglos es el que realizó François Chevalier en su obra $L a$ formación de los latifundios en México. Tierra y sociedad en los siglos XVI y XVII ${ }^{7}$. Delimita tres grandes acepciones para la dicha expresión: 1) Sentido primitivo de choza, abrigo más o menos provisional, cabaña o majada de pastores (ss. XVI y primera mitad del s. XVII); 2) Sentido de transición y de modesta explotación independiente (medidas

\footnotetext{
${ }^{1}$ Corominas, 1980-1991: 339.

${ }^{2}$ Cortés, 1988.

${ }^{3}$ Frago García, 1991: 340.

${ }^{4}$ Hay que aclarar en este punto que no es de nuestro interés abordar en este artículo el debate sobre el origen de la palabra rancho, sino tratarla en un contexto concreto, el bajocaliforniano, y cómo en el se va modificando su uso.

${ }^{5}$ Jiménez, 1972: 71, 74. Según este medievalista, el manuscrito en que nos ha llegado el ordenamiento concejil es de 1525-1535 (Frago García, 1991: 344).

${ }^{6}$ Real Academia Española, 1984: 340-341.

${ }^{7}$ Chevalier, 1976: 407-408.
} 
del s. XVII), y 3) Sentido de habitación aneja a una hacienda (segunda mitad del s. XVII y ss. XVIII-XIX).

Según indica Herón Pérez Martínez el término rancho tiene una fuerte impronta militar que va evolucionando a lo largo de los siglos y dependiendo del contexto espacial en el que se utiliza. Dicha voz ha sido usada para definir las instalaciones provisionales y más o menos desordenadas de los soldados (s. XIV), o para describir el hecho de llevarse algo por la fuerza (Juan de Castellanos en la segunda mitad del siglo XVI se refiere repetidamente a los rancheos o expediciones de saqueo ${ }^{8}$ ).

También recoge el sentido de alojamiento provisional o cabaña tal y como indicábamos anteriormente ya había hecho Chevalier. Será esta la acepción transportada América y fue el vocablo empleado por algunos de los cronistas-soldados para indicar las instalaciones de emergencia de que tuvieron que echar mana para sobrevivir en una tierra desconocida. Con reminiscencias de su pasado militar, el vocablo rancho ha sobrevivido hasta el presente con la vieja función de designar la vivienda rural, verdadero punto de partida de su evolución semántica, destaca Herón Pérez Martínez .

Atendiendo a la definición originaria del concepto rancho nos encontramos con ciertas dificultades puesto que siempre queda inevitablemente descrita desde la perspectiva del conquistador $\mathrm{y}$, por tanto, incompleta y sesgada. Si tomamos descripciones genéricas de diccionarios clásicos, tanto de 1737 como de 1780, nos encontramos que al delimitar las palabras "rancho" o "ranchería” ponen su énfasis en que se trataría de un grupo familiar, ligados a un espacio rural apartado, que se organizan para la realización de faenas cotidianas que tienen como su máxima plasmación en el comer juntos.

Si nos centramos en nuestro contexto bajocaliforniano encontramos en Venegas una acertada exposición del modelo de rancho indígena prejesuítico. Según dicho autor, cada nación ${ }^{10}$ o lengua se componía de diferentes rancherías mayores o menores en número según la feracidad del terreno, y cada ranchería era de una o muchas familias unidas por lazos de parentesco. Añade a esta característica principal la inexistencia de la institución de un poder dominante sobre la comunidad familiar que conforma la ranchería, sin embargo, incide en que eventualmente ciertos personajes se erigían de manera temporal y coyuntural para liderar acciones de recolecta, de mudanza u hostilidades. Pero en ningún caso estos cabecillas accedían a su posición por herencia, dignidad, logros o enfrentamientos. Estos serían los “caciques" a los que se mencionan reiteradamente otros jesuitas en sus escritos, como podrían ser Juan María Salvatierra o Miguel del Barco, que eran los representantes de sus rancherías ante los misioneros:

Este jefe o cacique los guiaba a los montes y a las costas del mar a buscar el sustento.- enviaba y recibía los recados de los comarcanos, los avisaba de los peligros, los inflamaba a la venganza de agravios, verdaderos o fingidos, de

\footnotetext{
${ }^{8}$ Pérez Martínez, 1994: 33-56.

${ }^{9}$ Ibíd.: 33-56.

10 "Este nombre "nación” en América, generalmente hablando, tiene distinta significación, que en Europa; aunque en Europa suele también tomarse de diferentes maneras. [...] En América, por lo regular, no habiendo entre los indios, que ahora se conquistan, ni distinción, o límite de provincias, ni separación de dominios, cuales se hallaron en los dos imperios de México, y del Perú, se reputan por una nación todos los indios, que usan un mismo lenguaje, sean pocos o muchos; bien vivan cerca unos de otros; bien derramados en distantes rancherías, o que si se diferencian en el idioma es poco, por ser unas lenguas dialectos de las otras de modo que puedan entenderse si mismos.” (Venegas, 1944: 61-62).
} 
otras rancherías o naciones; y los conducía con las guerrillas, robos, daños y muertes, que se hacían unos a otros ${ }^{11}$.

Los integrantes de cada ranchería, es decir, el conjunto de familias emparentadas entre sí, dentro de un esquema de linaje patrilineal ${ }^{12}$, solían tener una zona más o menos circunscrita, por la que andaban vagando, practicando la recolección y la caza. Se puede decir que el fundamento de la vida ranchera indígena reside en el nomadismo o seminomadismo. La movilidad estacional y dependiente de la fructificación de las plantas, de los ojos de agua y de los ciclos migratorios de la fauna (tanto terrestre como acuática), conforman una de las características esenciales de estos grupos. Es por esta razón por la que en los escritos de los misioneros se puede rastrear la localización de estos grupos familiares en sus puntos de movimiento. Un ejemplo lo encontramos de la mano de Juan María Salvatierra:

[...] caminamos esas tres leguas de nuevo descubrimiento [desde Londó], toda tierra muy llana y amena y con bastantes pastos para ganado, que nos alegró caminar por ella [...] el puesto donde estaban rancheados estaba cerca del aguaje, llamado en cochimí Nebeoyol, que en los derroteros de don Isidro de Atondo está en la segunda jornada que hizo de San Bruno para la contra $\operatorname{costa}^{13}$.

Miguel del Barco también aporta una interesante reflexión sobre el modo de vida de estas comunidades, destacando sobre todo las dificultades a las que se enfrentaban, según el parecer del misionero, por vivir en constante movimiento:

Moraban juntos los de cada ranchería en los parajes donde los forzaban a vivir la precisa necesidad y los pocos aguajes que hay en la tierra; pero fácilmente mudaban de rancho, según la precisión de ir a buscar su sustento en otros lugares. Dondequiera que paraban se acogían a la sombra de los árboles [...]. En el rigor del invierno vivían algunos en cuevas subterráneas que formaban o que les ofrecían en sus grutas los montes [...] Sus casa se reducen a un cercadillo de piedras superpuestas, en algunas partes de media vara de alto, y una en cuadro, sin más techo que el cielo. Casas verdaderamente tan estrechas y pobres que en su comparación pueden llamarse palacios las sepulturas. Dentro de estas casas no caben tendidos y les es forzoso dormir sentados dentro de aquel recinto. Más esto deberá entenderse de alguna u otra ranchería, o caso de alguna persona [...] Pues por lo común eran estos cercadillos de más de dos varas de diámetro, de suerte que por menos cabían dentro marido, mujer y los hijos pequeños. Eran redondos y de tres palmos o más de altos [... $]^{14}$.

En los espacios de usufructo de cada banda y clan existían bases o "residencias" estacionales que les permitían recorrer dichos territorios, ya fuera recolectando, pescando o cazando alimentos en específico. Cuando los alimentos predominantes cercanos a las bases o campamentos estacionales empezaban a escasear los individuos podían optar por trasladarse a su nuevo lugar dentro de la misma área tradicional, hasta terminar con los alimentos de esa temporada y pasar a una nueva área tradicional donde

\footnotetext{
${ }^{11}$ Ibíd.: 79-81.

12 León Portilla, 2000: 85.

13 Salvatierra, 1946: 121.

14 Barco, 1944: 268-270.
}

71 María del Mar Muñoz González. El sistema de rancherías: revisión de conceptos ... 67-85. 
se encontrarían con otros alimentos según el ciclo anual ${ }^{15}$. Los individuos se movilizaban en bandas buscando alimentos ${ }^{16}$, que la propia naturaleza producía en temporadas específicas y se agotaban más o menos rápidamente. El traslado en pequeños grupos era una estrategia para poder sobrevivir, ya que la producción básica del medio ambiente del área de estudio era demasiado escasa como para sostener una gran población. En una territorialidad de usufructo podía haber varias bandas que la ocupaban de manera simultánea pero pertenecían al mismo clan, o banda de clanes aliados. Además algunas se adelantaban o retrasaban según las disponibilidades de alimentos, sus conocimientos, tradiciones, amistades o enemistades entre otros ${ }^{17}$.

En una región cuyo régimen de lluvias es tan irregular e impredecible, como lo es la mayor parte de Baja California, era importante que las bandas de cazadoresrecolectores, que eran los únicos pobladores hasta la llegada de los exploradores europeos, fueran sumamente flexibles para poder modificar su tamaño y composición sin muchas complicaciones sociales o políticas en tiempos de escasez. Esto significa que en las temporadas de sequía o catástrofes naturales el tamaño de las bandas se reducía significativamente a partir de la división del grupo mayor en pequeñas unidades que podían sortear con mayor éxito las dificultades que el medio planteaba, pero en las épocas de abundancia, tales como la cosecha de las pitahayas o algunos otros productos temporales, las bandas se reunían en ceremonias multitudinarias que tendían a reforzar lazos de parentesco o afinidad ${ }^{18}$.

Hay que incidir en que no se debe caer en el error de confundir o suponer que las "rancherías" eran sinónimos de bandas de cazadores-recolectores, es decir, que una ranchería sólo era ocupada por una banda ${ }^{19}$, aunque si es posible que las bandas que estuvieran en una ranchería tuvieran alguna relación de parentesco ${ }^{20}$. Más bien parecería que varias bandas ocupaban un campamento estacional, que a su vez los misioneros denominaban ranchería.

\section{El modelo jesuítico de rancho: la Baja California}

Desde el inicio de su llegada, los misioneros se propusieron sustentar a las comunidades indígenas preexistentes. Sin embargo el hecho de que las misiones no dieran abasto para mantener sino a cortos grupos de nativos, demostró que los pueblos formados en la península alcanzaban muy pronto un límite crítico de crecimiento. Los religiosos advirtieron que, de no encontrar un medio de superar esa restricción de origen económico, amplios sectores de la población permanecerían insumisos y al margen del

\footnotetext{
15 "[...] todavía algunos historiadores suponen que la territorialidad nativa no variaba y que el factor "movilidad", característico de los grupos cazadores-recolectores, respondían esencialmente a la organización de actividades reproductivas estacionales. Es decir, como si el fenómeno de "arraigo" o "apego sentimental" propio de las poblaciones campesinas tradicionales y que se ha analizado a la luz de las formas de internalización de la cultura, fuera una manifestación necesaria en la definición de territorios étnicos" (Sheridan, 2004: 453).

16 "[...] la banda como una asociación de individuos, relacionados entre sí por el parentesco, que ocupan un territorio particular en el que comparten una serie de elecciones posibles para trasladarse compartir actividades con otros grupos similares, todo ello con el objeto de sacar el mejor partido de los recursos, que, por otro lado, nunca son los mismos a través del tiempo, en cuanto a su distribución y abundancia, de una estación a la otra o de un año al siguiente" (Rodríguez Tomp, 2006: 41).

${ }^{17}$ Magaña Mancillas, 2010: 96-97.

${ }^{18}$ Rodríguez Tomp, 2002: 32-33.

${ }^{19}$ Ibíd.: 37.

${ }^{20}$ Ibídem.
}

72 María del Mar Muñoz González. El sistema de rancherías: revisión de conceptos ... 67-85. 
proceso de evangelización. Fue necesario limitar, en cuanto a tiempo, la permanencia de la población nativa en las cabeceras de misión ${ }^{21}$.

En esta primera etapa se inició y desarrollo el sistema misional en manos de los jesuitas que fundaron diecisiete misiones ${ }^{22}$. La misión además de ser un centro religioso, constituía una pequeña unidad de producción en donde la tierra y los instrumentos de trabajo venían a pertenecer comunalmente a los habitantes indios de poblado. De esta manera, los misioneros actuaron al frente de las misiones como representantes y administradores de las propiedades misionales. Esta función administrativa de los jesuitas se extendió por un lapso de setenta años durante los cuales los padres gozaron de facultades extraordinarias para el control de todo el gobierno civil de California ${ }^{23}$.

El desarrollo de la agricultura y la ganadería en los centros misionales se veía como una de las condiciones que facilitarían la permanencia de los religiosos en la Península, y en la misma medida la reducción de los cazadores-recolectores sólo podría realizarse en que se desarrollaran como de producción agropecuaria ${ }^{24}$. Se había concebido que las misiones que la Compañía de Jesús tenía en las provincias de Sinaloa, Ostimuri y Sonora podían proporcionar un apoyo fundamental ${ }^{25}$. Aún así los religiosos fueron conscientes de que, para ser realmente viable, su proyecto colonizador exigía el desarrollo de un sistema productivo en el propio ámbito peninsular.

Una larga experiencia colectiva acumulada (tanto en territorio novohispano como en el resto de virreinatos) por misioneros de la Compañía de Jesús y de otras órdenes religiosas ${ }^{26}$ había demostrado que no era posible que los grupos humanos que vivían de la caza y la recolección adoptaran el modo de vida llevado por los misionerosconquistadores, si no se daba a aquella gente la oportunidad de conocer y practicar la agricultura y la ganadería, que era lo que, según se esperaba, los podría encaminar hacia el sedentarismo. Sin ofrecerles la seguridad del alimento no podían abandonar la vida nómada, ni siquiera transitoriamente $\mathrm{e}^{27}$.

Los jesuitas establecieron en sus misiones californianas un característico modo de funcionamiento, mediante el cual se procuró mantener a todos los neófitos bajo el influjo ejercido desde la cabecera de la misión. No todos los habitantes de las rancherías o pueblos circundantes pudieron ser simultáneamente acogidos en los poblados. Una

\footnotetext{
${ }^{21}$ Río, 1984: 135-136.

${ }^{22}$ Santa Gertrudis La Magna, Santa María de los Ángeles y San Francisco Borja, véase Amao Manríquez, 1997: 21-27.

${ }^{23}$ Río, 1971: 123.

${ }^{24}$ Ibíd., 2003: 96.

${ }^{25}$ López Sarrelangue, 1968: 1- 67.

${ }^{26}$ Fueron los misioneros franciscanos los primeros que lograron sedentarizar grupos de cazadoresrecolectores en el norte de la Nueva España. Cito aquí un texto del cronista franciscano José Arlegui (1851), en el que este religioso refiere los procederes y logros de fray Gerónimo de Mendoza, uno de los frailes menores que, a mediados del siglo XVI, iniciaron los trabajos de reducción entre los indios de Zacatecas y lo que hoy es el estado de Durango. Dice el cronista: "Juntos y congregados comenzaron [los indios que habitaban la región donde quedaría fundado el pueblo de San Francisco del Nombre de Dios, al noroeste de Zacatecas], con la industria de su devoto y religioso maestro, a cultivar y sembrar la tierra de maíz, calabazas y otras semillas que les dio el padre fray Gerónimo, y fue la cosecha tan abundante de todo lo que se admiraron los gentiles recién convertidos con la abundancia, teniendo desde entonces las palabras de su ministro como oráculos, experimentando que de su político obrar siembre les provenía mucho bien y que, teniendo lo necesario para su mantenimiento, para aprender la doctrina les sobraba tiempo" (Río, 2003: 96).

${ }^{27}$ Ibíd.: 96.
} 
precaria economía de subsistencia, como era la de los californios, tenía que ir aparejada con formas de organización social igualmente simples. Los misioneros emplearon el término ranchería para designar a cada uno de los grupos vinculados por lazos de parentesco que reconocían un conjunto de parajes determinados como zona habitual de residencia $^{28}$.

Es necesario detenernos para aclarar el concepto de cabecera de misión. Se trataba del pueblo fundado por los misioneros jesuitas (bien ex novo, bien sobre una ranchería preexistente) en la cual se localizaba la iglesia, la vivienda del misionero y el mínimo destacamento militar. Era por tanto el núcleo poblacional principal en el que residía, de ordinario, el misionero que tenía a su cargo muchas reducciones o pueblos pequeños que a los visitaba y asistía. Para el establecimiento de estas cabeceras se procuraba siempre buscar la cercanía de los ríos y arroyos, en palabras de los misioneros "para lograr que los indios se acostumbren a la vida cristiana y política reducidos a pueblos" 29 .

Algunos autores como Ignacio del Río señalan que debido a que las misiones no podían sostener una población permanente y recurrieron a un sistema de visitas periódicas. La participación de la población indígena en las labores agrícolas no fue continua sino que muchos de ellos seguían realizando actividades de cacería, pesca y recolección, lo que implicaría un desapego a la vida misional y a sus actividades ${ }^{30}$. Se reglamentaron las visitas de tal forma que asistieran grupos cortos de gente que después de pasar unos días en la correspondiente misión, debían retirarse a sus zonas habituales de residencia para dejar lugar en el poblado a otros contingentes semejantes. Cumplido su período de visita, los nuevos grupos también habrían de irse del pueblo para que prosiguiera la operación con las restantes rancherías de la comarca, que igualmente debía asistir a la cabecera misional por turnos y períodos determinados. Este método de visitas alternadas se generalizó rápidamente y hubo misiones en las que se aplicó desde el mismo momento en que fueron fundadas ${ }^{31}$. Tanto a las cabeceras misionales como a los pueblos-visitas se le adjudicaron nombres cristianos lo que implicaba una subordinación práctica y formal a la estructura misional ${ }^{32}$.

$\mathrm{Al}$ acercarnos a los textos elaborados tanto por misioneros jesuitas como por sus superiores en México podemos llegar a cierta confusión ya que algunas veces emplearon el término ranchería para nombrar a la banda misma y en otras al territorio donde ésta se asentaba. En vista de que las características generales de la forma de vida eran comunes a todos los indígenas, la principal diferenciación que los extranjeros pudieron hacer de las distintas parcialidades estaba basada principalmente en el factor

\footnotetext{
${ }^{28}$ El término ranchería alude al grupo y no supone ninguna forma de asentamiento permanente. "Moraban junto los de cada ranchería en los parajes donde los forzaba a vivir la precisa necesidad y los pocos parajes que hay en la tierra; pero fácilmente mudaban de rancho, según la presión de ir a buscar su sustento en otros lugares" (Venegas, 1944: 7. Río, 1984: 27).

${ }^{29}$ Venegas, 1944: 33.

${ }^{30}$ Martínez Zepeda, et.al. 2014: 120.

${ }^{31}$ Río, 1984: 135-136.

32 Además, era una práctica común este procedimiento unilateral, por ejemplo para la Antigua California en 1768 se señaló "que las nombradas rancherías en este Estado y los Padrones de que se deduce, no tienen sitios ni domicilios fijos en los distritos respectivos de las misiones que corresponden andan vagas, en los montes a excepción sólo de las pertenecientes a la de Nuestra Señora d Guadalupe que son rancherías verdaderas y reducidas a especie de pueblos, y alguna de la misión de San Francisco Xavier" en Estado general de las misiones, Puerto de la Paz, 20 de diciembre de 1768 (Magaña Mancillas, 2010: 36).
}

74 María del Mar Muñoz González. El sistema de rancherías: revisión de conceptos ... 67-85. 
lingüístico ${ }^{33}$. En general, en toda la región septentrional de la Nueva España fue común este término como mecanismo para facilitar la ubicación de los indios y así tener acceso a la mano de obra indígena ${ }^{34}$.

El padre Juan María Salvatierra, en los primeros meses de su estancia en la región de Loreto, vio con preocupación que los indios que habían asistido por algún tiempo a la doctrina se fueron de repente:

Lo que hay de raro es que lo mismo fue irse éstos que venir a poblar aquí otros de la misma nación, gente que aun pareció de mejores entrañas, que estuvieron aquí ocho días asistiendo a la doctrina como los otros. Y estos segundos también se fueron y vinieron a vivir aquí otros de la misma nación, aunque, al parecer, de natural más fuertes, pero van viniendo a la doctrina. Y se les predica a todos a Dios y a Jesucristo, aguardando si estas transmigraciones pararán en mal o en bien ${ }^{35}$.

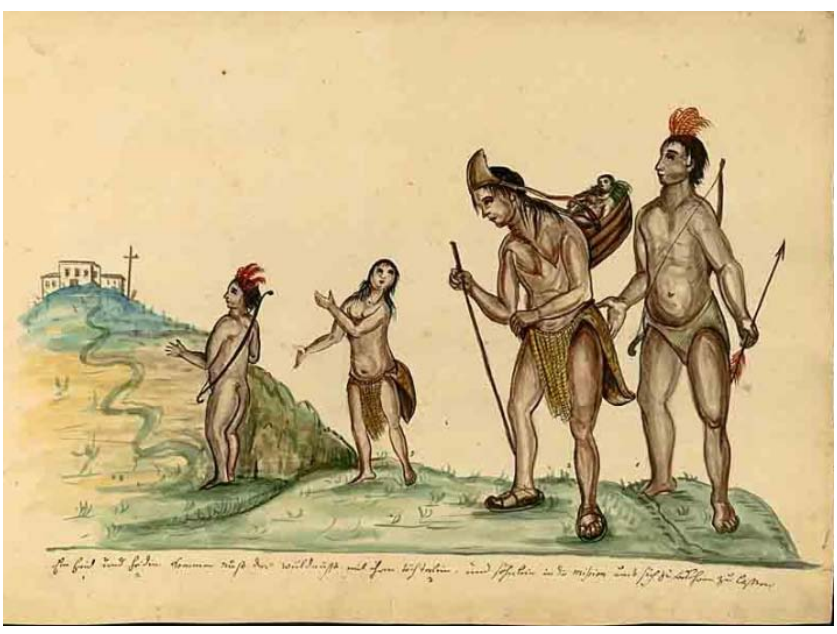

Fig. 1 Indígenas de la Península de Baja California según Ignác Tirsch ${ }^{36}$

Tanto el número de rancherías que hacían a un tiempo la visita como los períodos de permanencia en el pueblo variaron según el volumen de la población indígena existente en cada jurisdicción misional y la capacidad productiva que tenía cada pueblo en materia agrícola. Parece que lo más común era que el total de rancherías quedara dividido en cuatro conjuntos para que cada uno de éstos asistiera a la misión durante una semana al mes. Las rancherías se iban remudando cada semana en las cabeceras misionales. La idea era que se efectuara una ronda completa durante cada período lunar, o sea, cada cuatro semanas y muchas misiones tenían bajo su dependencia más de ocho rancherías.

Conocemos la organización de la misión de La Purísima en tiempos de Tamaral, que nos serviría de ejemplo del modelo esquematizado al que nos hemos referido y puede ser plasmado gráficamente de la siguiente manera ${ }^{37}$ :

\footnotetext{
${ }^{33}$ Rodríguez Tomp, 2002: 32-33.

34 “[...] la ubicación de las rancherías se convirtió para los militares, esclavistas y misioneros en el único medio para hacer visibles a los indígenas” (Sheridan, 2004: 447-468).

${ }^{35}$ Rodríguez Tomp, 2002: 32-33.

36 Tirsch URL: http://www.manuscriptorium.com (Última consulta: 12-Septiembre-2011).

${ }^{37}$ Salvatierra, 1946: 211-219.
} 
Fig. 2 Representación gráfica idealizada de la estructuración misional.

Ejemplo: Misión de la Purísima Concepción

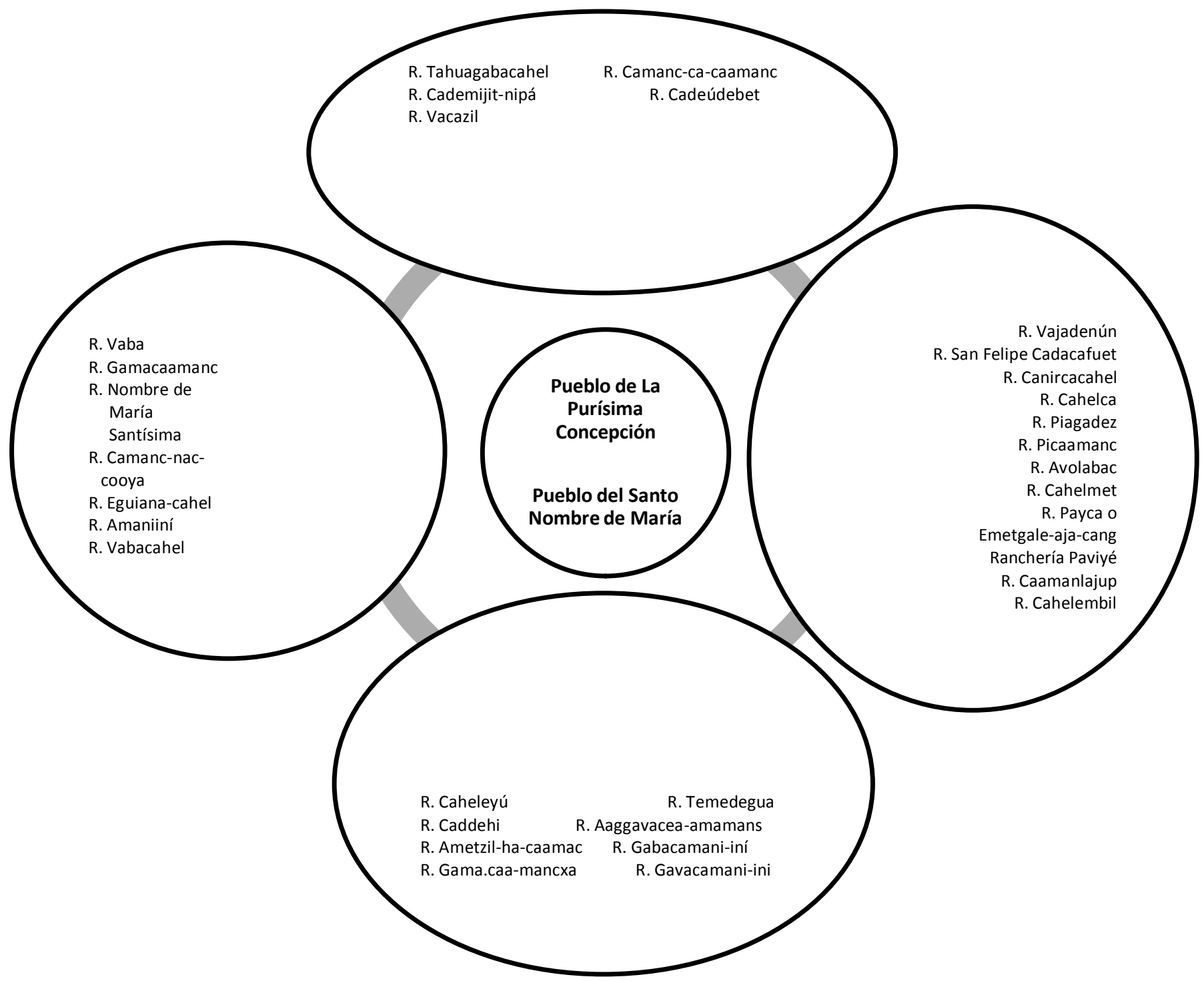

Este esquema está basado en la carta que el Padre Nicolás de Tamaral dirigida, en 1730, al padre visitador general sobre el estado de la misión de la Purísima del sur. Realiza una cuidada descripción geográfica de la localización latitudinal y referencial de cada uno de los cuatro espacios diferenciados por la topografía, así como la localización de las distintas rancherías y su relación con el relieve, las fuentes y cursos de agua, y la vegetación (que en la misma medida se usan como referencia denominativa por los habitantes nativos). Una distribución muy similar también la encontramos descrita para tres misiones la primera es la de Nuestra Señora de Loreto Conchó, la segunda es la de San Francisco Xavier Biaundó, la tercera es de Nuestra Señora de los Dolores llamada de los naturales Yodiviggé ${ }^{38}$.

38 AGI (Archivo General de Indias, Sevilla), GUADALAJARA, 134: Francisco María Píccolo, 10 de Febrero de 1702, Cartas diversas referentes a las misiones de los Padres Jesuitas en California (170103), Descubrimiento, conquista y misiones de California (1638-1728). ff. 666r-673v. 
Tamaral apunta que “dicha misión ocupa ochenta leguas de círculo por el aire el distrito de esta misión, que son muchas de territorio, atento a ser muchas las asperezas de la tierra en sierras y barrancas" ${ }^{39}$. Todo este territorio se organizaba en cuatro cordilleras, unas en el fondo de las sierras y otras en las costas del océano del sur. De este modo la fundación de misiones ordenaba el espacio. Mediante este sistema los jesuitas asumieron la distribución espacial existente pero introdujeron un modelo jerarquizado cuyo centro era la cabecera misional en torno a la cual orbitaban los pueblos de visita y rancherías. En este punto planteamos la posibilidad de que los pueblos de visita fueran una escala superior en la organización jerarquía territorial (y administrativa). Si bien, es verdad los misioneros usaban en sus escritos con mayor asiduidad el término "ranchería" que el de "pueblo de visita", en caso de que estos fuesen conceptualizados como sinónimos.

Sin embargo, hay que puntualizar que tal racionalización de los períodos de estancia y visita de las rancherías en la cabecera de la misión no sería más que un modelo y variaría según las características geográficas del entorno, las inclemencias climáticas, o las posibles alteraciones o modificaciones dentro de la comunidad. Es decir, no se limitaban a desplazarse según las dinámicas marcadas por la misión sino que conservaban sus patrones estacionales en cierta medida ${ }^{40}$.

En múltiples ocasiones se daba el caso de que algunos grupos, que vivían en lugares muy distantes de la correspondiente cabecera, hicieran la visita en forma más espaciada dilatando la temporalidad cíclica. Cuando los recursos de una misión eran más abundantes se siguió la costumbre de que todas las rancherías cercanas a la cabecera asistieran simultáneamente a ésta los domingos y festividades religiosas con el objeto de que con más asiduidad en los oficios de culto cristiano ${ }^{41}$. El momento paso obligatorio e ineludible por la cabecera de la misión de todas las rancherías era el momento del bautismo. Este sacramento suponía, no sólo cristianar a las comunidades, sino también un modo de control, cuantificación y ligazón al ciclo de visitas periódicas:

[...] la misión iglesia nombrada Nuestra Señora de Loreto en que después de la instrucción necesaria bautizaron trescientos adultos de las rancherías inmediatas viniendo cada día de lo interior de la tierra otras naciones a pedir ministro que los vayan a bautizar y poner en pueblos y policía ${ }^{42}$.

La vida cotidiana de los antiguos habitantes de la península sufrió grandes modificaciones cuando entraron en los planes de evangelización y conquista de la Corona española. Este proceso significó un descalabro para las comunidades indígenas puesto que las obligó a modificar una buena parte de sus antiguas costumbres. Durante este período las epidemias tuvieron efectos devastadores en la población indígena, lo que influyó en las misiones propiciando la decadencia de algunas de ellas, en su mayoría las ubicadas en el sur de la península. Al abandonarse algunos sitios misionales, éstos fueron solicitados y otorgados como mercedes de tierras a soldados y ex soldados en esa zona. Estos militares, que procedían por lo general de familias de las provincias como Chiametla, Culiacán, Sinaloa, Ostimuri y Sonora, o el Gran Nayar,

\footnotetext{
${ }^{39}$ Salvatierra, 1946: 211.

40 Ibíd: 115.

${ }^{41}$ Río, 1984: 136-137.

42 AGI (Sevilla), GUADALAJARA, 134: Bernardo Rolandegui, 4 de Julio de 1701, Cartas diversas referentes a las misiones de los Padres Jesuitas en California (1701-03), Descubrimiento, conquista y misiones de California (1638-1728), ff. 652r-655r.
} 
practicaron actividades trasmitidas de padres a hijos y que fueron adaptadas a la realidad californiana ${ }^{43}$.

Los distintos grupos indígenas no se alejaron definitivamente de sus actividades económicas tradicionales debido a que la administración misional no era capaz de proporcionar alimento para toda la población. Continuaron con sus prácticas de cazadores-recolectores a pesar de estar ya sujetos al orden misional, pues llegaban a los establecimientos sólo por cortas temporadas, y después tenían que regresar a sus ancestrales recorridos. La nueva distribución de los espacios afectaba notablemente a los territorios de recorrido de las bandas, obligándolas a hacer constantes modificaciones de sus recorridos y límites. Esta situación, unida a las enfermedades antes desconocidas por los nativos y a la represión contra las bandas más rebeldes, provocó un rápido declive demográfico. Sin embargo, los supervivientes trataron de mantener las actividades y formas de apropiación de los recursos que podían asegurar su subsistencia. Esta lucha habría de durar en lagunas zonas de la península el tiempo que permanecieron las misiones ${ }^{44}$.

\section{La dotación de un carácter ganadero al término "rancho"}

Cuando los misioneros jesuitas emprendieron la tarea de evangelizar a la población autóctona de California llevaron la experiencia las misiones del noroeste novohispano y de los consecutivos intentos de colonización en la península que precedieron a su establecimiento ${ }^{45}$. Sabían que para lograr el éxito en su empresa requerían, por una parte, del envío de bastimentos del exterior, y por otra, conseguir que las tierras misionales produjeran por lo menos una parte de los productos necesarios para la subsistencia. Era necesario asegurar una provisión de alimentos por medio de la práctica de la agricultura y la ganadería para ofrecerles a los indígenas y que estos consideraran el abandono de la vida nómada como una alternativa ${ }^{46}$.

Los misioneros encontraron varias limitaciones para impulsar el desarrollo de la agricultura y la ganadería, entre ellas, la más importante fue la carencia de agua ${ }^{47}$. Pese a esto, y como señala Ignacio del Río, es muy probable que los misioneros intentaran introducir todos los cultivos posibles de forma experimental para poder lograr así el autoabastecimiento $^{48}$. Los terrenos cultivables eran generalmente pequeños y en ocasiones el agua se llevaba por medio de canales a los sitios misionales, en otras se llevó tierra a los sitios donde abundaba agua ${ }^{49}$. Indudablemente este tipo de acciones llevaron a cabo la modificación del paisaje $\mathrm{e}^{50}$.

Desde los inicios del establecimiento de las primeras misiones los jesuitas siempre llevaron consigo cabezas de ganado tanto para la alimentación como para su uso en los viajes pastorales y de exploración. Esto devino en la aparición de dos tipos de

\footnotetext{
43 “También les protegía de las espinas, cuando avanzaban entre los matorrales espinosos en el paisaje de la península" (Amao Manríquez, 1997: 21-27).

${ }^{44}$ Rodríguez Tomp, 2002: 52-53.

${ }^{45}$ Río, 2003: 117.

${ }^{46}$ Martínez Zepeda, 2014: 117.

${ }^{47}$ Ibíd., 2014: 118.

${ }^{48}$ Ibíd., 119.

${ }^{49}$ Ignacio del Río da como ejemplos las misiones de Santa Gertrudis y Santa Rosalía de Mulegé (Río, 2003: 98)

${ }^{50}$ Martínez Zepeda, 2014: 119.
} 
ganadería en la Península bajocaliforniana: la cimarrona y la de rodeo. Como la aridez casi general de los suelos donde se fundaban las misiones no permitía practicar la ganadería estabulada, los misioneros dejaban que el ganado vacuno vagara por los montes para que libremente buscara las zonas de pastizales. Al paso de los años, este sistema de pastoreo libre dio lugar a que gran parte de las reses se convirtiera en ganado cimarrón que sólo los vaqueros misionales podían atrapar en las constantes correrías que se organizaban poco después del tiempo de lluvias ${ }^{51}$. Esta ganadería cimarrona estaba integrada por ese ganado montaraz que, además, constituía en un principio el mayor porcentaje. La de rodeo se formaba con el ganado doméstico que explotaban los rancheros de las inmediaciones de los centros mineros ${ }^{52}$. Misioneros y vaqueros conocían con relativa exactitud los rumbos que tomaban las bestias en busca de agua y comida, lo que permitió tener un cierto control sobre ellas. Cuando se requería, los encargados iban a buscar las reses al campo, y para sacrificarlas, ya para arrearlas hacia la misión. Por lo tanto, excepto para algunos indios nativos, estos animales, aunque montaraces, no era piezas de caza, sino activos de la economía misional ${ }^{53}$.

En estas actividades agro-ganaderas tuvieron un papel fundamental los soldados que bajo el amparo de los jesuitas llegaron a California. Los soldados y sus familias se establecieron primero en las misiones y posteriormente, conforme conocieron el territorio y sus posibilidades, solicitaron y recibieron donaciones de tierras donde establecieron ranchos ${ }^{54}$. Los jesuitas adoptaron la política de dar facilidades al personal empleado en la guardia del presidio (de Loreto), sobre todo, a los soldados de confianza y que se mostraban leales a los misioneros. Se les permitía criar algún ganado y disponer de parajes para el pastoreo de los animales en terrenos de las misiones: como por ejemplo podemos citar al capitán Esteban Rodríguez Lorenzo ${ }^{55}$ y su familia, que tuvieron su propio hato de ganado.

A las incipientes actividades agrícolas y ganaderas hay que añadir, desde los primeros años, los trabajos mineros en las cercanías de Santa Ana y San Antonio. Allí también se establecieron estancias de ganado. Sus propietarios generalmente vivían en ellos y, aun cuando también se dedicaran a la minería, se encargaban directamente de atender su ganado. Esto ocurría por no hallar quienes quisieran emplearse como vaqueros, que era más común, o porque tales dueños no tuvieran solvencia económica como para mantener a sueldo algunos trabajadores ${ }^{56}$.

La insuficiente producción agrícola convirtió a la ganadería en una actividad de importancia estratégica para la permanencia del sistema misional en la Península. Por las crónicas y testimonios de la época, conocemos que la carne y otros productos animales constituyeron parte primordial de la alimentación en los pueblos de misión, en ocasiones, casi su único sustento cuando la cortedad de las cosechas y la falta de abasto externo dejaban a las misiones desprovistas de granos ${ }^{57}$. Como con la agricultura, la ganadería misional bajacaliforniana fue esencialmente doméstica, es decir, miraba a la

\footnotetext{
${ }^{51}$ Amao Maríquez, 1981: 46.

52 Ibíd.: p. 131.

53 Altable, 2002: 86-87.

${ }^{54}$ Martínez Zepeda, 2014: 118.

55 Amao Maríquez, 1981: 47.

${ }^{56}$ Ibíd.: 51-52.

${ }^{57}$ Altable, 2002: 83.
} 
satisfacción de las necesidades internas de la misión y no a la obtención de excedentes comercializables $^{58}$.

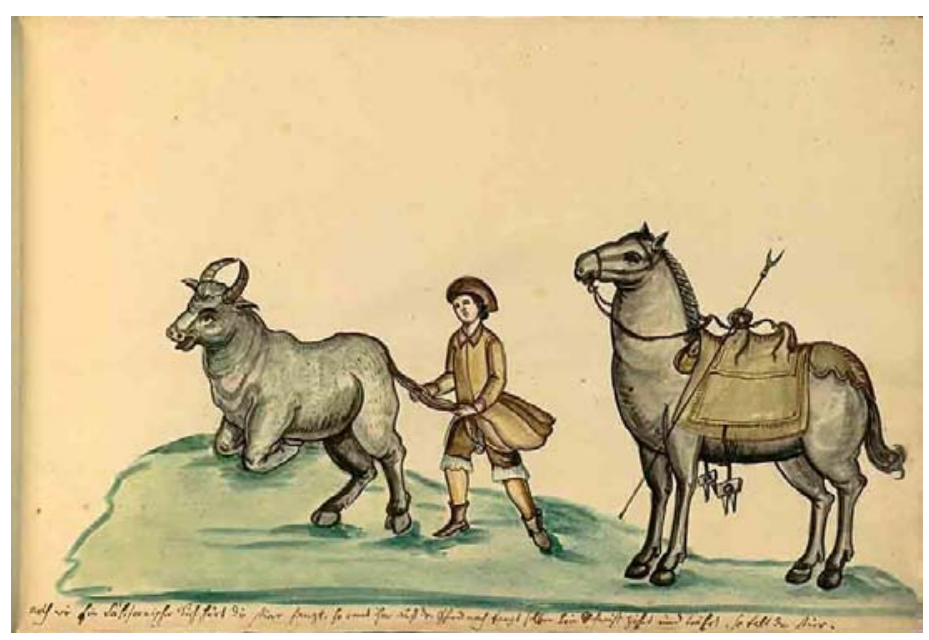

Fig. 3 Ganadero según Ignác Tirsch ${ }^{59}$

\section{Ganado, desierto y frontera: trilogía en un territorio inhóspito}

Según Micheline Cariño Olvera el aprovechamiento integral de los recursos naturales en la organización de la sociedad y la economía rancheras constituye uno de los modelos de relaciones hombre/espacio que caracteriza la ecohistoria de la Baja California. Esta estrategia fue desarrollada por los colonos que poblaron el espacio peninsular desde mediados del siglo XVIII, basándose en la herencia de conocimiento de los indios californios tenían de la geografía regional ${ }^{60}$, en el aprendizaje de las técnicas llevadas por los misioneros que permitían adaptar al entorno peninsular la forma de vida occidental y, finalmente, en la experiencia agroganadera adquirida por estos individuos en las provincias misionales de la contracosta.

Autosuficiencia, austeridad y aprovechamiento ${ }^{61}$ fueron los tres pilares en los que los rancheros sudcalifornianos basaron sus actividades económicas, su organización social y hasta su concepción del mundo. Pausada y dispersamente se fueron asentando en sitios que por sus características fisiográficas permitían la práctica de la ganadería y de una agricultura complementaria. De este modo se establecieron los núcleos familiares que fundaron los primeros ranchos ganaderos peninsulares estableciendo de este modo el modelo de rancho predecesor del modelo actual.

La existencia de una fuente de agua permanente fue la condición indispensable para establecer un rancho, lo que explica el aislamiento y la dispersión de éstos. Los manantiales, además de ser escasos, eran recónditos, alejados unos de los otros y de difícil acceso. El uso integral de los recursos naturales y la austeridad, que habían heredado de las culturas autóctonas, fueron la norma de vida y de producción. Así, para un máximo aprovechamiento del agua los rancheros, aunaron a esas tradiciones ancestrales, los sistemas de irrigación implantados por los jesuitas ${ }^{62}$.

\footnotetext{
${ }^{58}$ Ibíd.: 87.

59 Tirsch, URL: http://www.manuscriptorium.com/?q=es (Última consulta: 12-Septiembre-2011).

${ }^{60}$ Cariño Olvera, 2000: 28.

61 Ibíd.: 29.

${ }^{62}$ Ibídem.
}

80 María del Mar Muñoz González. El sistema de rancherías: revisión de conceptos ... 67-85. 
La base de este modelo productivo lo constituyó la ganadería. Al igual que en la economía misional, el ganado aportaba una valiosa cantidad de recursos destinados tanto a la alimentación como a la fabricación de útiles y vestimentas. Al término del siglo XVIII ${ }^{63}$ la población de la Baja California dependía casi exclusivamente de la actividad ganadera y fue entonces cuando la vital economía ranchera forjó su papel pionero en la historia sudcaliforniana ${ }^{64}$.

La organización espacio-temporal consistía en utilizar al máximo los limitados recursos forrajeros de la naturaleza sudcaliforniana ${ }^{65}$ : los recorridos de los rebaños en los terrenos de agostaderos de cada rancho llevaron establecimiento de ciertos parajes que tanto por su composición, como por su dispersión y empleo, recuerda el sistema que para el aprovechamiento del medio tuvieron los antiguos californios en sus territorios de recorrido. Este modelo llevó a los rancheros a fijar una estrecha relación con el marco ecológico en el que se establecieron, basada en el ahorro de energía, en las diferentes condiciones que determinan los ciclos de lluvia y sequía, y sobre todo en el principio fundamental de evitar la sobreexplotación.

Los rancheros incorporaron a la ganadería la práctica de la agrícola para producir sus alimentos de origen vegetal. Distribuían su trabajo y el terreno apto para el cultivo en dos zonas: la de irrigación y la de temporal ${ }^{66}$. En las huertas idearon un sistema de policultivo escalonado en tres niveles, así tanto el espacio y como el agua se aprovecharon al máximo. Pese a que fueron un elemento esencial en la economía ranchera la superficie de cultivo fue muy reducida y su producto fue dedicado al autoconsumo. De manera semejante a la agricultura de las huertas la de temporal fue considerada como complementaria.

Con el proceso de decadencia de las misiones la población de Baja California intensificó sus actividades agropecuarias, aprovechando de las tierras roturadas por los misioneros, y fundando ranchos particulares. Estas propiedades eran de tipo ganadero, principalmente, y estaban basadas en una autosuficiencia familiar precaria, en una cultura rudimentaria ligada a la supervivencia en una zona ecológicamente hostil para los estándares occidentales. Fue este contexto el que propició el acercamiento cultural a los indígenas del entorno, primero con los cristianizados y después con los no cristianizados o gentiles ${ }^{67}$.

Por lo que respecta a la situación demográfica de esta última fase del modelo ranchero al que nos estamos refiriendo, según Cariño Olvera ${ }^{68}$, la baja densidad de población resultante de la dispersión en el establecimiento de los ranchos fue un factor esencial en la subsistencia de esta sociedad. La concentración de la población hubiera requerido un incremento de la producción en cada rancho, más allá de cierto límite de

\footnotetext{
63 "En la primera mitad del siglo XIX, la ganadería dejó de ser una forma elemental de subsistencia para perfilarse como una actividad económica preponderante. La posesión de sitios de ganado mayor (1755,51 ha.) empezó a dar a la tierra un valor económico y político que nunca antes había tenido en la región. El aumento de la producción ganadera tuvo como resultado cierto crecimiento demográfico a causa del mejoramiento de las condiciones de vida. Entre 1768 y 1857 quedó formalizado el establecimiento de los primeros ranchos sudcalifornianos y la economía ranchera como una actividad de suma importancia". (Ibíd., 28-29).

${ }^{64}$ Ibíd.: 28.

${ }^{65}$ Ibíd.: 31-32.

${ }^{66}$ Ibíd.: 28.

${ }^{67}$ Garduño, 2005: 27.

${ }^{68}$ Ibíd.: 28.
} 
explotación del ecosistema. El aumento de los miembros de cada familia determinaba el establecimiento de un nuevo rancho.

La Baja California es considerada, a partir de este momento, una región-frontera, un país fronterizo, donde las misiones construyeron marcas territoriales a través del poder social y religioso ${ }^{69}$. Era un territorio relativamente desocupado, en las orillas de lo que sería el Virreinato (y años más tarde, la nación). Un territorio de colonización tardía y de características medioambientales muy peculiares. En fin, un territorio en el que los diversos grupos humanos, en diversas épocas, de diversas procedencias y por diversos motivos, se dieron a la tarea de construir sociedad(es) y cultura(es) en un espacio geográfico en donde apenas existen recursos naturales y sociales ${ }^{70}$.

Fueron los rancheros, que hemos tratado en este artículo, los que aprovecharon las tierras en decadencia o abandonadas por los indígenas cristianizados y misioneros, fundaron propiedades particulares de tipo ganadero con base en la autosuficiencia de una organización familiar, modificaron el régimen de propiedad. En todo el proceso mantuvieron al indígena como mano de obra, favoreciéndose de la cultura nómada, que no prestaba atención a la posesión de la tierra sino a los recursos que sobre ella se producían de manera natural o cultivada y que permitían la caza, pesca y recolección ${ }^{71}$.

\section{A modo de conclusión}

El principal objetivo de los misioneros jesuitas era la integración de las comunidades indígenas a los modos y normas de la Corona española y de la cristiandad. La consecución de este objetivo fracasó en Baja California a causa de las limitaciones que el medio geográfico impuso. El número de neófitos que podía albergar una misión estaba estrechamente relacionado con la disponibilidad de comida y el nivel de sedentarización en el que se podría hallar cada grupo o banda. La California jesuítica se caracterizó por la inestabilidad de sus núcleos misionales de población, constantemente desintegrados y recompuestos por el sistema de visitas alternadas ${ }^{72}$.

La California jesuítica se caracterizó por la inestabilidad de sus núcleos misionales de población, constantemente desintegrados y recompuestos a consecuencia de la práctica del sistema de visitas alternadas. Mínima fue la población nativa que tuvo la opción de incorporarse a los pueblos de misión por períodos más o menos largos o bien de hacerlo de forma definitiva ${ }^{73}$. Podemos decir que ante todo destaca el sentido de provisionalidad, característico del rancho ${ }^{74}$.

Este sistema de dominación y organización del espacio pretendía una doble finalidad: por un lado conservaba, cierta medida, las dinámicas de movilidad ancestrales de los pueblos que habitaban la Baja California a la llegada de los conquistadores, y de este modo, los misioneros pretendía subsanar la radicalidad que supondría una sedentarización definitiva y el consecuente proceso de aculturación. Por otro lado, los jesuitas necesitaban economizar y aliviar la carga que se imponía sobre la frágil e incipiente agricultura practicada en las cabeceras de misiones. La modificación del lugar

\footnotetext{
${ }^{69}$ Ibíd.: 11.

${ }^{70}$ Ibíd.: 7.

${ }^{71}$ Ibíd.: 11-12.

${ }^{72}$ Río, 1984: 137.

${ }^{73}$ Ibíd.: 137.

${ }^{74}$ Pérez Martínez, 1994: 33-56.
} 
de residencia y, por tanto, de las formas de vida fue más que evidente. La distribución del espacio a modo de estructura (ideal o modélica) concéntrica polarizada por la cabecera misional a la que acudían cíclicamente las rancherías colindantes y dependientes, representó un dinamizante del proceso de aculturación.

Este contexto dio lugar a la aparición de una economía de oasis. Las aisladas fundaciones jesuitas florecieron en torno a las fuentes de agua preexistentes. En este sentido, es claro que la colonización misional que promovieron los misioneros jesuitas, se localizó en parajes de la península donde se hallaban nichos con ecosistemas más propicios para la ocupación humana. De ellos ya se aprovechaba la población autóctona y siguiendo este modelo, también de ellos se sirvieron los religiosos jesuitas para establecer las misiones.

En esta economía de oasis tiene lugar la evolución del concepto de rancho. Pese a sus modificaciones de uso y las posibles contradicciones en el mismo, el término rancho tiene en su esencia y definición el 'movimiento'. Se utilizó primero para definir bandas o grupos de personas que se desplazaban de un lugar a otro buscando alimentos, así como para definir sus asentamientos temporales. Más tarde se utilizaría para denominar aquellas incipientes y limitadas explotaciones ganaderas de época jesuítica en las que, por las limitaciones ambientales, el ganado se movía en libertad (era cimarrón) y sólo cuando era necesario se reunía. Este es, en última instancia, el matiz que ha perdurado hasta nuestros días.

Para terminar, sólo añadir el esquema que aparece en la Figura 4 que nos puede servir de síntesis conceptual del contenido de este artículo y que nos permite conocer de un rápido vistazo cómo ha sido la evolución del término rancho en el concepto de la Baja California en la época de los misioneros de la Compañía de Jesús.

\section{Fuentes primarias}

AGI (Sevilla), GUADALAJARA, 134: Bernardo Rolandegui, 4 de Julio de 1701, Cartas diversas referentes a las misiones de los Padres Jesuitas en California (1701-03), Descubrimiento, conquista y misiones de California (1638-1728), ff. 652r-655r.

AGI (Sevilla), GUADALAJARA, 134: Francisco María Píccolo, 10 de Febrero de 1702, Cartas diversas referentes a las misiones de los Padres Jesuitas en California (1701-03), Descubrimiento, conquista y misiones de California (1638-1728). ff. 666r-673v.

Tirsch, Ignác; Codex Pictoricus Mexicanus, 2. pol. XVIII. stol. (c. 1762). Biblioteca Nacional de Praga, República Checa. URL: http://www.manuscriptorium.com (Última consulta: 12-Septiembre-2011).

\section{Bibliografía}

Altable; Francisco (2002). "I. De la caza y recolección a la explotación colonial de los recursos naturales: 2. La economía misional” en VV. AA. Historia general de Baja California Sur. 3 Economía regional, México: Plaza y Valdés, pp. 21-166. 
Amao Maríquez, Jorge Luis (1981). El establecimiento de la comunidad minera en la California Jesuítica, La Paz, B. C. S.: Colección Cabildo, Serie Premios.

(1997). Mineros, misioneros y rancheros de la Antigua California, México: Plaza y Valdés, INAH.

Barco, Miguel del (1944). Historia natural de la Antigua California / Edición, introducción y notas de Miguel León Portilla; Madrid: Historia 16, Crónicas de América 53.

Cariño Olvera, Martha Micheline (2000). “Tres modelos para el análisis histórico de las relaciones hombre/espacio en Sudcalifornia (1500-1940)” en Bernabéu Albert, Salvador (Ed.) El Septentrión Novohispano: Ecohistoria, Sociedades e imágenes de frontera; Consejo Superior de Investigaciones Científicas, Colección Tierra Nueva e Cielo Nuevo, 39; Madrid.

Corominas, Juan (1980-1991), Diccionario crítico etimológico castellano e hispánico [DECH], con la colaboración de José A. Pascual. Madrid: Gredos.

Cortés, Hernán [1519-1526] (2015). Cartas de relación, Mario Hernández, Madrid: Historia 16, 1988, en Corpus del Nuevo Diccionario Histórico Español Versión 3.0.: http://web.frl.es/CNDHE/view/inicioExterno.view (Última consulta: 14/05/2015).

Chevalier, François (1976). La formación de los latifundios en México. Tierra y sociedad en los siglos XVI y XVII, México: Fondo de Cultura Económica.

Frago García, Juan (1991). “Rancho ‘vivienda rural o finca de campo’: un andalucismo léxico más del español en América” en Revista de Filología Española, vol. LXXI, n ${ }^{\circ} 3 / 4$, CSIC.

Garduño, Everardo et alii. (2005). La frontera interpretada. Procesos culturales en la frontera noroeste de México. Mexicali, Baja California: Universidad Autónoma de Baja California, Centro de Investigaciones Culturales-Museo: CONACULTA: CECUT: Congreso del Estado de Baja California.

González Jiménez, Manuel (1972). Ordenanzas del Concejo de Carmona. Sevilla..

León Portilla, Miguel (2000). La California mexicana: ensayos acerca de su historia, México: Instituto de Investigaciones Históricas, Universidad Nacional Autónoma de México.

López Sarrelangue, Delfina E. "Las misiones jesuitas de Sonora y Sinaloa, base de la colonización de la Baja California”. En Revista Estudios de Historia Novohispana, 2, México: Instituto de Investigaciones Históricas, UNAM, 1968, pp. 1- 67.

Magaña Mancillas, Mario Alberto (2010). Indios, soldados y rancheros. Poblamiento, memoria e identidades en el área central de las Californias (1768-1870), La Paz, Baja California Sur: Gobierno de Estado de Baja California Sue, Instituto Sudcaliforniano de cultura, El Colegio de Michoacán, Consejo Nacional para la Cultura y las Artes.

Martínez Zepeda, Jorge; León Velazco, Lucila del Carmen y Cruz González, Norma del Carmen (2014). "Los ranchos de la etapa misional y su herencia cultural en Baja California” en Sorroche Cuerva, Miguel Ángel (ed.), Baja California. Memoria, 
herencia e identidad patrimonial, Granada: Editorial Universidad de Granada, pp. 115-154.

Pérez Martínez, Herón (1994). "El vocablo ranchero y sus derivados: génesis, evolución y usos”. En Barragán López, Esteban et alii. (Coord.) Rancheros y sociedades rancheras, Zamora, Michoacán: El Colegio de Michoacán; ORSTOM; CEMCA.

Real Academia Española (1984). Diccionario de la lengua española. Madrid: EspasaCalpe.

Río, Ignacio del (1984). Conquista y aculturación en la California Jesuítica 1697-1768. México: Universidad Nacional Autónoma de México, Instituto de Investigaciones Históricas, Serie Historia Novohispana/Número 32.

- (2003). El régimen jesuítico de la Antigua California, México: Universidad Nacional Autónoma de México, Facultad de Filosofía y Letras, 1971. Se ha consultado también una reedición posterior: México: Universidad Nacional Autónoma de México, Instituto de Investigaciones Históricas.

Rodríguez Tomp, Rosa Elba y Altable, Francisco (2002). “I. De la Caza y recolección a la explotación colonial de los recursos naturales: 1. La economía de los aborígenes de Baja California” en Historia general de Baja California Sur. 3 Economía regional, México: Plaza y Valdés.

- (2006) Los límites de la identidad. Los grupos indígenas de Baja California ante el cambio cultural, La Paz: Gobierno de Baja California Sur / Universidad Autónoma de Baja California Sur.

Salvatierra, Juan María (1946). Misión de la Baja California /con introducción, arreglo y notas por Bayle, Constantino; Madrid: La Editorial Católica, S. A.

Sheridan, Cecilia (2004). “Territorios y fronteras en el noroeste novohispano”. En Salas Quintanal, Hernán y Pérez-Taylor, Rafael, Desierto y fronteras: el norte de México y otros contextos culturales, Ciudad de México: UNAM, Plaza y Valdés Editores.

Tirsch, Ignác; Codex Pictoricus Mexicanus, 2. pol. XVIII. stol. (c. 1762). Biblioteca Nacional de Praga, República Checa. URL: http://www.manuscriptorium.com (Última consulta: 12-Septiembre-2011).

Venegas, Miguel (1944) Noticias de la California y de su conquista temporal y espiritual hasta el tiempo presente (formada en México año de 1732); Vol. 1; México: Layac. 